Institute of $\mathbf{F}_{\text {ood and }} \mathbf{A g r i c u l t u r a l}_{\mathbf{S}} \mathbf{S}_{\text {ciences }}$

\title{
Environmental and Chemical Effects on Home Furnishings ${ }^{1}$
}

Marie Hammer ${ }^{2}$

\section{Environment Affects Furnishings}

In Florida, the sunlight, humidity and the warm temperature can be very harsh on furnishings. These climatic conditions can also influence the damage done by pollutants such as airborne soils, oxides of sulfur and nitrogen, and ozone that can damage furnishings.

A variety of chemical products used in the home can also be damaging. The chemicals lie dormant until a change in humidity, temperature, moisture or sunlight occurs to activate the chemical reaction. For example, relatively high humidity is necessary for bleaching action to begin. Similarly, many chemical agents require wetness to trigger reaction. This means discoloration can result after a textile product has been cleaned or water has activated the chemical.

Furnishing a home requires a sizable investment of money. When environmental conditions and household chemicals cause damage to the furnishings, the resulting loss is significant. The seriousness of the problem depends on the type and concentration of air pollutants in the area where you live, the climatic conditions in the area and the sensitivity of furnishings to the particular conditions and pollutants to which they are exposed.

High humidity conditions along Florida's coast and south Florida vary from those in north Florida and certainly from other parts of the country. Large cities with high traffic can expect more fuel combustion products, including oxides of sulfur and nitrogen to be present in the air. The type of industry in the area can also affect the environmental conditions.

Studies show that the conditions for potential damages vary from one locale to another, from one house to another in the same locale, from one room to another in the same house. Houses on the same block may be built differently and have different heating, cooling and humidity control systems so the furnishings are subjected to different environments. It is not unusual to have furnishings deteriorating or fading faster in one room in a

1. This document is FCS 3156, one of a series of the Department of Family, Youth and Community Sciences, Florida Cooperative Extension Service, Institute of Food and Agricultural Sciences, University of Florida. Publication date: August 2002. First published: April 1990. Reviewed: August 2002 Please visit the EDIS Web site at http://edis.ifas.ufl.edu

2. Written by Marie Hammer, former Professor, Housing/Home Environment, Department of Family, Youth and Community Sciences, Cooperative Extension Service, Institute of Food and Agricultural Sciences, University of Florida, Gainesville, 32611 and reviewed by Nayda I. Torres, Professor, Family and Consumer Economics, Department of Family, Youth and Community Sciences, Cooperative Extension Service, Institute of Food and Agricultural Sciences, University of Florida and Dale Dorman, Extension Housing and Environment Specialist - Emeritus, Cooperative Extension Service, University of Georgia.

The use of trade names in this publication is solely for the purpose of providing specific information. UF/IFAS does not guarantee or warranty the products named, and references to them in this publication does not signify our approval to the exclusion of other products of suitable composition.

The Institute of Food and Agricultural Sciences is an equal opportunity/affirmative action employer authorized to provide research, educational information and other services only to individuals and institutions that function without regard to race, color, sex, age, handicap, or national origin. For information on obtaining other extension publications, contact your county Cooperative Extension Service office. Florida Cooperative Extension Service / Institute of Food and Agricultural Sciences / University of Florida / Christine Taylor Waddill, Dean 
house, possibly from differing amounts of exposure to sunlight.

A knowledge of the environmental conditions and household chemicals that have the potential to damage furnishings, coupled with information about fabrics and furnishings, will help you to be a more satisfied consumer.

\section{Sunlight}

Textile Home Furnishings. Sunlight can fade dyed fabrics and cause damage by weakening some fibers. While this weakening effect can be enhanced by the presence of airborne particles, the damage caused by other contaminants (e.g., oxides of sulfur) can be increased in the presence of sunlight (see Table 1).

The durability of a fabric exposed to sun depends on its fiber content, construction method, or even the types of yarns and dyes used and finishes applied. The fiber should resist damage from sunlight, and both the yarns and the weave should be uniform and even.

Cotton, silk, acetate, rayon and nylon are quite sensitive to sunlight damage; acrylic and polyester are less sensitive. Glass fiber is highly resistant to damage caused by sunlight.

Color choice can be important when selecting fabrics that will be exposed to the sun. Light colors tend to reflect heat; dark colors absorb heat. The more sunlight the fabric absorbs, the more chance for the fibers to be damaged. Medium intensity colors show sun fading less quickly than bright, vivid ones.

A protective backing, such as a metallic coating or lining, possibly acrylic, helps protect drapery fabrics from sun damage and fading.

Furniture. Steady prolonged exposure to ultraviolet rays from the sun can cause a chemical change in the finish, resulting in fine hairline cracks. This condition is often referred to as "crazing." When choosing furniture, make practical choices that will withstand light and heat.
Wood furniture will change color when exposed to sunlight, and the extra heat will dry it out, causing cracking, splitting, and loosening of glued joints. How much the color will change depends on the natural pigments in the wood, how the piece was finished, the care it has received and the exposure it receives.

While dark woods will lighten, some of the very light woods will actually get darker. Most of the change in color will occur during the first year. Stains actually accelerate the color change. Solid woods are more likely than veneers to shrink or swell because solid wood is less flexible.

Proper care will provide some protection. Use furniture oil or wax to help seal the wood. Avoid products that contain alcohol, which accelerates drying of the wood.

Your best approach is to keep wood furniture out of direct sunlight. Keep draperies, blinds, or shades drawn to shield furniture during intense sunlight hours. If this isn't possible, plan to rearrange furniture every month or so by rotating pieces in and out of the sun to keep damage to a minimum.

Accessories. Accessories are subject to damage from exposure to the sun. Sunlight can crack oil pigments in oil paintings, fade water colors and deteriorate paper and canvas in a very short time. Acrylics are more resistant but are still not recommended in areas of direct exposure.

Some finishes on ceramic lamps, ashtrays, etc. may craze, then crack after prolonged exposure to the sun. If your accessories are exposed to sunlight, rotate the accessories from unshaded to shaded areas. Also move accessories so exposure does not create dark spots on the furniture under the accessories. Rugs, and furniture should be rotated to minimize fading.

\section{Humidity}

Textile Home Furnishings. In the presence of high humidity, the action of atmospheric chemical contaminants on dyes and fibers is often 
accelerated. The combination of oxides of nitrogen and/or sulfur that is present in some areas with moisture in the air produces acid conditions that can have significant deteriorating effects. Research has shown, for example, that the most damage caused by the oxides of sulfur occurs when moisture and sunlight are present.

Fibers vary in their ability to absorb moisture. Cottons, linens, rayons and wool absorb moisture readily, while synthetics absorb more slowly. Olefins absorb very little or no moisture. In drapery fabrics, too much absorption can cause some fabrics (such as rayons) to sag and lose their shape. Moisture also can carry airborne pollutants and contaminants into the fabric, speeding fiber deterioration.

Still another indirect damaging effect of high humidity, especially in warm climates, is that it enhances the growth of mold and mildew. Mildew can cause both discoloration and deterioration of fabrics.

The fabrics most susceptible to damage by molds and mildew are those made from cellulose (cotton, linen, rayon) or protein (wool, silk) fibers. Although the fungi will grow on and discolor fabrics made of synthetic fibers, the latter generally are not damaged by mold and mildew.

Furniture. Vapor, in the form of humidity, moves through wood more rapidly and easily than liquids do, causing damage as it progresses through the furniture. When combined with extremes of temperature, the pace is increased. Wood shrinks when exposed to a combination of low humidity/temperature and swells when its environment is hot and humid. That's why drawers that stick in summer may open easily in winter. This subtle expansion and contraction of furniture can result in swollen joints, hairline cracks in the finish, blistering or buckling of a finish, warping of furniture sections (drawers, legs) or, in extreme cases, delamination of veneered surfaces.

To avoid humidity/temperature damage, try to control the environment. Adjust the humidity with humidifiers or dehumidifiers -- whichever is necessary -- to keep the air between $30 \%$ to $50 \%$ moisture and maintain temperatures within the $60^{\circ}$ to $80^{\circ} \mathrm{F}$. range. (The same environmental conditions that are comfortable for people are good for furniture.)

Avoid placing furniture in the direct path of heat or humidity control sources (heaters, registers, air conditioners, humidifiers) or storing it in areas where temperature and humidity are not controlled, such as attics, garages, or enclosed porches.

\section{Airborne Soils}

Textile Home Furnishings. Airborne soils that collect on the surfaces of textile home furnishings not only mar the appearance of the fabric but also can have damaging effects. These effects usually are indirect.

Fabrics exposed to a dirty environment need frequent cleanings. With each cleaning the fabric is subjected to an array of stresses which include abrasion, heat, and detergent or solvent which can cause a progressive loss of fiber strength and/or fabric color. High soil levels also may require the use of more aggressive detergents or cleaning solvents than would be needed to remove light soiling. The acceleration in fabric damage that can result means a shortened wear-life of the drapery, upholstery, or other textile home furnishing product.

Because synthetic fibers are nonabsorbent and accumulate electrostatic charges, they are generally more prone to attract airborne particles of soil than are natural fibers or man-made cellulose fibers (rayon).

Detergent solutions are not readily absorbed by synthetic fibers. Therefore, fabrics made of synthetic fibers may require the use of more aggressive cleaning products than fabrics made of natural fibers or man-made cellulosics (rayons).

Because aggressive detergent products are often highly alkaline, the sensitivity of a fabric to an alkaline cleaning product can be important in the choice of a home furnishing textile that will be used 
in a "dirty" environment. Olefin fibers are highly resistant to the effect of alkali. Cotton, linen, aramid, glass, modacrylic, nylon, and polyester are generally resistant to its effects. The protein fibers (silk, wool) are most sensitive to high alkalinity.

Porous fabrics behave like an air filter; airborne soils collect on them as the air sweeps or flows through the fibrous structure. Therefore, draperies and curtains made of "open" fabric structures are highly susceptible to soiling from airborne particles.

Furniture. Keep furniture clean and protected from wear and damage. Dust is actually thousands of tiny, airborne particles of fiber, earth and silica. Airborne fumes from heating, cooking, smoking or air pollution are also deposited on furniture. (You probably noticed the dull, dingy film that collects on windows between cleanings. The same kind of soil settles on furniture.)

\section{Ozone}

As the number of automobiles increases, the ozone level in Florida is expected to creep upward. It is a problem particularly in the state's urban areas. Primarily an indirect product of automobile emissions and industrial sources, ozone is commonly a major component of smog.

When ozone is present in the atmosphere in sufficient quantities ozone fading can occur. Often confused with fume fading, which is generally caused by nitrogen dioxide, ozone fading may occur on dyes that are colorfast to fume fading.

Humidity is a complicating factor: high humidity can accelerate ozone fading, while very little or no color change seems to occur at relative humidity levels below 65 percent.

\section{Oxides of Sulfur}

There is strong evidence that sulfur dioxide, a by-product of the combustion of sulfur-containing coal and fuel oil, significantly damages some textiles. The most damage occurs when moisture (humidity) levels are high and when sunlight is present. It is responsible for damage and the reduced life expectancy of household linens and home furnishings such as curtains and carpets (including backing yarns).

Cellulosic and nylon fibers are most sensitive to damage by sulfur dioxide; other fibers, including polyester, modacrylic, and olefins, seem to be resistant. The fibers that are most resistant to the effects of acid conditions include glass, modacrylic, olefin, polyester, and wool. Acrylic and aramid are resistant to the effect of most acids. Acetate, cotton, linen, rayon and nylon are said to be weakened or harmed by acids. Although silk is resistant to organic acids (such as acetic vinegar and citric acids), it is harmed by other acids.

Although certain dyes used on wool and cellulosic fibers are said to be mildly sensitive to sulfur dioxide, the presence of sulfur dioxide in the air does not pose a serious fading problem. It can, however, cause red dye on wool to change to yellow. One study shows that moisture can be a significant factor in the fading of wool caused by sulfur dioxide.

\section{Oxides of Nitrogen}

Oxides of nitrogen are by-products of the combustion fuels including natural gas and gasoline. Complaints about the fading of fabrics attributable to nitrogen oxides have been found in situations where families use gas clothes dryers or gas heaters, or live in areas where smog is a problem.

In addition to fiber damage caused by the oxides of nitrogen, change in the color of a fabric can also be a problem. Studies show that nitrogen dioxide can react with:

1. a number of dyes to cause noticeable color changes,

2. certain fabric additives to cause a yellowing of white fabrics, or 
3. the chemical given off by some polyethylene storage bags and wrappings to cause yellowing of white fabrics stored in them.

Although most often associated with the fading or color change of acetate fabrics, the so-called "fume fading" has been observed in fabrics made of other fibers too.

Moisture, sunlight and heat are complicating factors. They contribute to the reaction of nitrogen oxides with other substances in the air to form new compounds that, in turn, can cause damage and/or fading of fabrics.

Cotton and rayon fabrics appear to be most susceptible to the damaging effects of the oxides of nitrogen in areas where high humidity is a contributing factor.

Dyes vulnerable to fading by nitrogen dioxide (mainly blue, green and violet) include some of the dyes used on cotton, rayon, acetate and nylon fabrics. "Solution dyed" man-made fibers are resistant to fume fading.

White or pastel fabrics that have been treated with such additives as optical brighteners, softeners, soil-release finishes, and certain processing agents are most susceptible to the yellowing effect of nitrogen dioxide. Most of the observed discoloration has occurred on nylon, acetate and permanent press (polyester-cotton) materials. Yellowing associated with storage of white fabrics in polyethylene bags or wrapping is said to be common to most fabrics, regardless of fiber content.

\section{Consumer Awareness}

The damage to textile fabrics caused by air pollution and other environmental conditions represents serious losses to consumers. The selection of home furnishing fabrics which are most resistant to potentially damaging environmental conditions in your home can result in important savings to you and your family (see Table 2). Major damaging effects include:

\section{- $\quad$ Fading}

- fabric colored with dyes with limited colorfastness to sunlight

- certain dyed nylon carpets by ozone

- permanent press polyester/cotton fabrics by ozone

- certain dyed cellulosic, acetate, and nylon fabrics caused by nitrogen dioxide and/or ozone

\section{- Loss of Strength}

- especially of cotton, silk, acetate, rayon and nylon fabrics, from exposure to sunlight

- fabrics made of cellulosic and nylon fibers when exposed to acid conditions that result when sulfur oxides and moisture are present

- discoloration and loss of strength of certain fabrics caused by mildew, especially fabrics made of natural and man-made cellulosics and used where high levels of humidity and heat prevail

\section{- Soiling}

- fabrics exposed to a dirty atmosphere

- $\quad$ synthetic fibers are generally more prone to attract airborne particles of soil than natural fibers or man-made cellulose fibers (rayon)

\section{- Yellowing}

- undyed white fabrics by nitrogen dioxide

\section{Chemicals Affect Furnishings}

Many chemical products found in the home can cause damage to furnishings if carelessly handled. Certain environmental conditions can activate chemical reactions (see Table 3). Many chemicals will remain unnoticed until there is a change in 
humidity, temperature, moisture or sunlight to promote a reaction. This means that discoloration often results shortly after a textile product is cleaned. Frequently the professional cleaner is accused of causing the problem.

People do not realize that these household products frequently contain ingredients which can cause irreparable damage to valuable carpets, rugs, upholstery fabrics and other household furnishings if they are spilled or allowed to come in contact with them.

Some of the more common chemical products known to cause problems include medications, certain cosmetics, all household bleaches, disinfectants, furniture polish, certain plant foods, fertilizers and insecticides. One fiber manufacturer has estimated the number of household products to be more than 50 .

Basically, there are two types of spots that can appear on home furnishing textile materials including carpet and upholstery fabrics. The first type of spot is the common stain which occurs when food is spilled or dirt is tracked in. These spots are usually apparent immediately and action can be taken to remove them without damage to the carpet or upholstery fabric.

In these cases, professional cleaners, the product manufacturer or the retailer can be consulted for care information. Carpet and rug care guides deal with regular care and common stain problems. This information is available from the fiber producer, the manufacturer, and from your County Extension Office.

The second type of spot or discoloration of carpets and home furnishing fabrics is the chemical stain. More insidious than the common stain, the chemical stain is caused by the introduction of foreign substances to the surface of textile products, which actually changes or destroys the dye. The time between contact and appearance of the stain could be days or months. Generally, nothing can be done to restore the dye to its original color.
There are a few known dyes that are resistant to chemical degradation. Such dyes have limited application and restricted choice of colors.

\section{Acne Medication and Skin Creams}

Benzoyl peroxide is an active ingredient in acne medications, fade or age creams, some foot care preparations and some pet shampoos. It is a strong oxidizing agent capable of destroying most dyes used in carpet and upholstery fabrics. Other textiles such as pillowcases, sheets, and towels may also be affected.

Spots caused by benzoyl peroxide may appear hours, days or months after the contamination depending on temperature and humidity. This means that the original source of the spill could have been forgotten by the time the spot appears.

An additional problem with this chemical is that compounds containing benzoyl peroxide are not water soluble. They are difficult to wash off the hands or face. The user may believe the substance has been washed off when it really has not.

Most benzoyl peroxide spots begin as orange or dark yellow depending on the dyestuff used. As time and the oxidation process continue, the yellow stain will get lighter in color. On blue carpets, however, these spots may appear slightly pinkish or white. In some cases, the spot may appear to be yellow with an orange halo around it, moving toward yellow as the spot grows. Manufacturers have estimated that a high percent of unidentifiable spots on carpets can be attributed to this chemical.

\section{Bleaches}

Most people are aware that misuse of household bleaches on colored fabric may remove the color as well as stubborn stains. Accidental spills on carpets and upholstery fabrics are equally damaging.

Chlorine bleaches are the most universally used. The so-called "all-fabric" bleaches, although slower acting, can cause bleaching and dye 
bleeding. Swimming pool chemicals tracked into the home can bleach carpets and rugs. Also, most mildew inhibitors can bleach, which will affect textiles if used improperly.

Spots caused by chlorine are generally yellow.

\section{Acids and Alkalis}

As little as one percent of hydrochloric acid in solution can cause spots on fibers. Hydrochloric acid can cause pink or orange spots in carpet. It can also cause some red dye stuffs to turn bright blue.

Some toilet bowl cleaners contain as much as 10 percent hydrochloric acid. Corn and callous removers contain phosphoric and glacial acetic acid. Tile cleaners also contain acid which can cause color changes as do certain food preparations. Stomach acid is essentially 10 percent hydrochloric acid. This means that vomit can cause permanent spots on carpets and upholstery if not promptly removed and/or neutralized.

Strong alkaline substances, such as those found in drain cleaners and oven cleaners are equally damaging when they come in contact with carpets and other textile products. Strong alkalis will destroy the fabric itself, as well as cause spots and stains.

\section{Urine Stains}

Urine from children and pets can cause permanent stains to carpet and upholstery fabrics if not promptly removed. The characteristic ammonia-like odor of urine will be replaced by a musty odor.

Spots caused by urine may be a dull yellow or even red.

\section{Plant Foods and Fertilizer}

Spills of some liquid plant foods or leakage from house plants can cause color changes in carpet. Spots of this kind usually develop near the backing and progress upward through the pile to the surface. Stains of this type may not be apparent for months.

\section{Insecticides}

Some pesticide chemicals may cause appreciable discoloration of textile dye, resulting in an irreversible color change. These products vary widely in active ingredients, concentration, formulation, application, effectiveness and toxicity. A number of tests conducted in Kansas and Miami show that high temperature, humidity and light exposure accelerate color change in some insecticides/dye types.

\section{Furniture Polish}

Chemicals in furniture polish can act as a catalytic agent to destroy dyes. On carpet, the discoloration usually occurs around the base of a piece of furniture and can remain hidden until the furniture is moved.

\section{Consumer Awareness}

The following suggestions may be helpful in identifying the cause of chemical spots and stains on carpets and other textile products:

1. Where is the spot located in the house? In teenagers' rooms, one would suspect acne medication containing benzoyl peroxide when stains appear on towels, bedsheets, carpets and clothing. Green discoloration along baseboards suggests insecticides. In the living or dining room where houseplants are kept it could be leakage from pots containing plant food. Stains around the base of furniture could be contamination from furniture polish. The important thing is to isolate the cause of the spot and take whatever steps are necessary to prevent future exposure.

2. Was the chemical substance spilled or tracked onto the carpet from some other areas? The pattern of the stain indicates how it happened. Spills often resemble explosions. Tracking commonly leaves a clearly defined shape like a handprint or footprint. Tracking stains are 
usually limited to the tips of the tufts. Where tracks come from could indicate the cause.

3. Does the spot have an odor? If the spot smells different from the rest of the carpet, it is obvious that a foreign substance is present. The odor can be a clue to its identity.

4. What color are the spots? Different chemicals react differently to different colors and dyestuffs. As we have noted, they also react differently under various climatic conditions.

a. In general, red spots on tan or beige carpet may suggest strong acids.

b. Yellow stains indicate reactions caused by strong oxidizers or bleaches

c. Green or blue stains may indicate sunlight combined with a catalyst.

Dye spots caused in the mill are rare and are always darker, never lighter, than the background. Once a textile product has been chemically stained, there is nothing that can be done by the individual or by the professional cleaner to restore the material to its original color and condition. If a stain has occurred, the source of contamination should be identified and steps taken to prevent further contamination from the same cause. The homeowner can prevent spots from occurring in the first place by showing proper respect for household chemicals and treating them with due caution. Stained areas can be repaired by cutting out a section of the carpet and replacing it with a "scrap" piece cut from a closet or an inconspicuous area. Repairing carpet in this manner can be very satisfactory depending on the condition of the carpet, the type of carpet and location of the spot.

\section{References}

American Textile Manufacturers Institute, in cooperation with: Science and Education Administration, Extension Service, U.S. Department of Agriculture, Washington, D.C.

Florida State of the Environment, Florida Department of Environmental Regulation, Tallahassee, FL 32399 
Table 1. Choosing fabrics on the basis of environmental effects.

Pollutants/Conditions

Airborne Soils

Excessive soiling. Loss of fiber strength and

fabric color from frequent

cleanings with

aggressive procedures

and cleaning products. conductivity accumulate static charges that attract soil. Non-absorbent fibers may require the most aggressive cleaning products and procedures. Olefin fibers are highly resistant to effects of

alkaline cleaning products; wool and silk are most sensitive.

\section{Oxides of Nitrogen}

Ozone

Sunlight

Humidity

\section{Primary Effects}

Loss of fiber strength caused by acid presence of sulfur oxides conditions resulting from (and moisture)
"Fume fading" of colors. Fading of colors. Yellowing of certain

undyed white fabrics.
Loss of fiber strength. Fading of colors Enhanced photochemical oxidation of sulfur dioxide, hence the formation of acid condition.

\section{Consumer Considerations}

Cellulosic and nylon fibers are most sensitive to effects of acid conditions. (mainly of Certain dyes (mainly blue, green, or viole cellulosics, acetate, and nylon are sensitive to fume fading. "Solution dyeing" of man-made fibers minimizes the fume fading problem. Undyed white fabrics to which certain finishes (optical brighteners, softeners, soil release) have been applied may be susceptible to yellowing by nitrogen oxides.
Blue and red colors seem to be affected by ozone fading to a greater extent than other colors. Dyes most vulnerable to ozone fading include disperse dyes (used on triacetate polyester, and acetate) and direct dyes (used on cellulosics). Permanent press cotton/polyester fabrics and some nylon carpeting have shown sensitivity to ozone fading.
Cotton, silk, acetate, rayon, and nylon are sensitive to damage by sunlight. Acrylic and polyester are resistant to damage, while glass fibe is highly resistant. Light colors and those of medium intensity show sun fading less than dark colors or those of high intensity. Protective backings or coatings (of curtain and draperies) and stated guarantees are indicators of sunlight resistance.
Acceleration of effects of atmospheric pollutants on dyes and fibers.

Weakening and

discoloration of fabrics by mildew, the growth of which is supported by highly humid conditions and warmth.

Cellulosic and nylon fabrics are most sensitive to acid conditions, the formation of which is enhanced by presence of moisture in the air. Cellulose (cotton, linen, rayon) and protein (wool, silk) fibers are most susceptible to damage by mildew. Synthetic fibers are discolored but generally not damaged by mildew.

Source: Goodrich, Jean. Environmental Effects on Textile Home Furnishings/Purdue University, West Lafayette, Indiana Cooperative Extension Service, 1985 
Table 2. A guide for selection of fibers for the home.

\begin{tabular}{|c|c|c|c|c|c|c|}
\hline $\begin{array}{l}\text { Generic } \\
\text { Fiber }\end{array}$ & Reaction to Sunlight & Reaction to Heat & Absorbency & Tensile Strength & Uses in the Home & $\begin{array}{l}\text { Other } \\
\text { Characteristics }\end{array}$ \\
\hline Acetate & $\begin{array}{l}\text { Slight loss of strength. } \\
\text { Little color loss. }\end{array}$ & Little degradation. & Low & Low & $\begin{array}{l}\text { Drapery, drapery lining, } \\
\text { curtains, bedspreads. }\end{array}$ & \\
\hline Aramid & & $\begin{array}{l}\text { High temperature } \\
\text { and flame resistant. } \\
\text { Stable to broad } \\
\text { temperature range. } \\
\text { Sensitive to relative } \\
\text { humidity changes. }\end{array}$ & & & $\begin{array}{l}\text { Blended with rayon for } \\
\text { bath blankets. }\end{array}$ & $\begin{array}{l}\text { Resistant to abrasion, } \\
\text { excellent toughness } \\
\text { and dimensional } \\
\text { stability. }\end{array}$ \\
\hline Acrylic & $\begin{array}{l}\text { Very little loss of } \\
\text { strength. No } \\
\text { discoloration. High } \\
\text { resistance to } \\
\text { degradation from acid } \\
\text { and sunlight. }\end{array}$ & $\begin{array}{l}\text { Little degradation. } \\
\text { Resistant to damage } \\
\text { by battery acid, acid } \\
\text { fumes, soot and } \\
\text { smoke. }\end{array}$ & Low & Medium & $\begin{array}{l}\text { Window coverings, } \\
\text { upholstery, carpeting, } \\
\text { blankets, awnings, and } \\
\text { umbrellas. }\end{array}$ & Full range of colors \\
\hline Cotton & $\begin{array}{l}\text { Gradual loss of } \\
\text { strength. Gradual } \\
\text { yellowing. }\end{array}$ & $\begin{array}{l}\text { Excellent resistance } \\
\text { to degradation by } \\
\text { heat. }\end{array}$ & Medium & Medium & Upholstery & \\
\hline Glass & None & None & None & None & Window coverings & \\
\hline Leather & $\begin{array}{l}\text { No loss of strength. } \\
\text { Slight discoloration. }\end{array}$ & $\begin{array}{l}\text { Embrittlement. } \\
\text { Stabilized by care. }\end{array}$ & Low & High & Upholstery & \\
\hline Linen & $\begin{array}{l}\text { Gradual loss of } \\
\text { strength. }\end{array}$ & $\begin{array}{l}\text { Discolors at high } \\
\text { temperatures. }\end{array}$ & High & High & Upholstery & \\
\hline Modacrylic & $\begin{array}{l}\text { Very little loss of } \\
\text { strength. }\end{array}$ & $\begin{array}{l}\text { Little degradation. } \\
\text { Inherently flame } \\
\text { resistant. }\end{array}$ & Low & Medium & $\begin{array}{l}\text { Upholstery, window } \\
\text { coverings, blanket } \\
\text { fabric, wall coverings, } \\
\text { hardware, kitchenware, } \\
\text { paint brushes, hair } \\
\text { brushes. }\end{array}$ & $\begin{array}{l}\text { Does not attract } \\
\text { moths, silverfish or } \\
\text { other insects. Springs } \\
\text { back to original shape } \\
\text { after stretching and } \\
\text { crushing. }\end{array}$ \\
\hline Nylon & $\begin{array}{l}\text { Gradual loss of } \\
\text { strength. Little color } \\
\text { loss. }\end{array}$ & Little degradation. & Low & High & $\begin{array}{l}\text { Carpet, windows, rugs, } \\
\text { upholstery. }\end{array}$ & \\
\hline
\end{tabular}


Table 2. A guide for selection of fibers for the home.

\begin{tabular}{|c|c|c|c|c|c|c|}
\hline $\begin{array}{l}\text { Generic } \\
\text { Fiber }\end{array}$ & Reaction to Sunlight & Reaction to Heat & Absorbency & Tensile Strength & Uses in the Home & $\begin{array}{l}\text { Other } \\
\text { Characteristics }\end{array}$ \\
\hline Olefin & $\begin{array}{l}\text { Moderate strength loss. } \\
\text { Gradual embrittlement. } \\
\text { Can be stabilized. }\end{array}$ & $\begin{array}{l}\text { Moderate } \\
\text { decomposition. } \\
\text { Embrittlement }\end{array}$ & None & Medium & $\begin{array}{l}\text { Primary backing for } \\
\text { tufted carpet; for carpet, } \\
\text { pile upholstery fabrics, } \\
\text { wall fabrics. }\end{array}$ & $\begin{array}{l}\text { Rot and mildew } \\
\text { resistance. Does not } \\
\text { produce lint. Retains } \\
\text { color in Florida sun. }\end{array}$ \\
\hline Polyester & $\begin{array}{l}\text { Very gradual strength } \\
\text { loss. No discoloration. }\end{array}$ & Little degradation. & Low & Medium & $\begin{array}{l}\text { Windows, upholstery, } \\
\text { cushions for patio } \\
\text { furniture, bedding. }\end{array}$ & $\begin{array}{l}\text { Holds its shape } \\
\text { without shrinking or } \\
\text { stretching in moist, } \\
\text { humid climate. } \\
\text { Resistant to wrinkling. } \\
\text { Non-allergic. } \\
\text { Odorless. }\end{array}$ \\
\hline Rayon & $\begin{array}{l}\text { Gradual loss of } \\
\text { strength, affected more } \\
\text { than cotton. }\end{array}$ & Little degradation. & High & Low & $\begin{array}{l}\text { Upholstery, window } \\
\text { coverings, draperies, } \\
\text { table linens. }\end{array}$ & \\
\hline Silk & $\begin{array}{l}\text { Moderate loss of } \\
\text { strength, affected more } \\
\text { than cotton, depends } \\
\text { on dye and additives. }\end{array}$ & $\begin{array}{l}\text { Less affected than } \\
\text { wool. }\end{array}$ & Medium & High & Upholstery & \\
\hline Vinyl & $\begin{array}{l}\text { No loss of strength, } \\
\text { slight discoloration. }\end{array}$ & $\begin{array}{l}\text { Gradual } \\
\text { embrittlement. }\end{array}$ & None & High & Upholstery & \\
\hline Wool & $\begin{array}{l}\text { Loss of strength, } \\
\text { gradual fading. }\end{array}$ & $\begin{array}{l}\text { Loses softness from } \\
\text { prolonged exposure. }\end{array}$ & High & Low & Upholstery, carpeting. & \\
\hline
\end{tabular}

Adapted from: Fabrics from the Energy-Conscious Home, Michigan State University, Extension Bulletin E-1772, July, 1984. 
Table 3. Chemical reactions and carpet damage affecting dye.

\begin{tabular}{|c|c|c|}
\hline Household Product & Chemical & Reaction \\
\hline Toilet Bowl Cleaner & $\begin{array}{l}\text { Some toilet bowl cleaners } \\
\text { contain hydrochloric acid and } \\
\text { coloring agents. }\end{array}$ & $\begin{array}{l}\text { Acid may dissolve nylon while } \\
\text { the coloring agent stains }\end{array}$ \\
\hline Tile Grout Cleaner & Phosphoric acid. & \\
\hline Acne Medication & $\begin{array}{l}\text { Numerous products are } \\
\text { available over the counter that } \\
\text { contain benzoyl peroxide. }\end{array}$ & $\begin{array}{l}\text { Strong oxidizing agent is } \\
\text { capable of destroying most } \\
\text { dye stuffs used in carpet and } \\
\text { household fabrics. }\end{array}$ \\
\hline
\end{tabular}

Conditions

Damage

dye stuffs used in carpet and household fabrics. to begin. The time between the

Benzoyl peroxide is in some of these products.

\section{Shampoo Mange Remedy}

\section{Bleaches}

Drain Cleaners, Strong

Alkalis, and Oven

Cleaners

\section{Industrial Solvents (for}

pain, arthritis,

backache, injuries,

muscular aches)

\section{Insecticides}

Spots can look and feel chalky
Chlorine bleach (sodium All can cause bleaching and hypochlorite), "all fabric" oxygen bleaches, swimming pool chemicals, mildew killers that contain bleach.

Jelled sodium hydroxide

DMSO (dimethyl sulfoxide)

DDVP, Malathion, Orthene, Sumithion (most common in consumer products that claim to be safe on the label but may not be). dye bleeding but are slower acting. Affects textiles if used indoors.

Application of chemical applied in stream instead of a

fan shaped mist to the

baseboards. An overall

misting can be used for fleas
Relatively high humidity is necessary for bleaching action contact and appearance of the spot could be days (spill forgotten).

Some dyes turn bright red.

Spots begin as orange to yellow as the dye is bleached and progresses to lighter yellow as oxidation proceeds. On blue carpet, spots can appear slightly pink, red or exhibit an orange ring or halo that moves outward as the spot grows. Other household textiles can be affected. Yellow spots occur. from presence of bentonite (fullers earth), which absorbs skin oils.

Bleaches carpet

Bleaching occurs

Loss of color on carpet is due to solvent.

Chemicals mentioned are in some off-the-shelf insecticides which have labels that recommend use on carpet.

Products can change dye colors chemically. Example: red dyes in beige color turn blue, giving a green cast. Humidity influences color change. 
Table 3. Chemical reactions and carpet damage affecting dye.

\begin{tabular}{|c|c|c|c|c|}
\hline Household Product & Chemical & Reaction & Conditions & Damage \\
\hline Plant food & & $\begin{array}{l}\text { Causes oxidation spots, } \\
\text { usually near backing and then } \\
\text { progresses upward to the } \\
\text { surface. Spot may not be } \\
\text { apparent for months. }\end{array}$ & $\begin{array}{l}\text { Spills of liquid plant foods or } \\
\text { leakage from flower pots. }\end{array}$ & Dull yellow or brown in color. \\
\hline Urine & & & $\begin{array}{l}\text { Spots begin at the backing and } \\
\text { progress upward. The } \\
\text { ammonia-like odor eventually } \\
\text { becomes a musty odor. }\end{array}$ & $\begin{array}{l}\text { Dull yellow or red. Clean with } \\
\text { lukewarm water and apply solution } \\
\text { of half water/half vinegar. }\end{array}$ \\
\hline $\begin{array}{l}\text { Vomit (human or } \\
\text { animal) }\end{array}$ & Hydrochloric acid & & & $\begin{array}{l}\text { Causes spots if not cleaned well. } \\
\text { Neutralized with baking soda or an } \\
\text { ammonia solution. }\end{array}$ \\
\hline
\end{tabular}

Information from: Chemical Spots and Stains on Carpet and Rugs, The Carpet and Rug Institute. 